\title{
Cumplimiento de las obligaciones tributarias del impuesto al valor agregado en la empresa SERVI PETROL, C.A.
}

\author{
Compliance with the tax obligations of the value added tax in the company \\ SERVI PETROL, C.A.
}

\section{Cumprimento das obrigações tributárias do imposto sobre valor agregado na empresa SERVI PETROL, CA}

\author{
$\triangle$ Noremilia Guerrero \\ noremilia85_09@hotmail.com
} Aceptado: diciembre 2019 Publicado: enero 2021

Universidad del Zulia. Núcleo Costa Oriental del Lago, Venezuela
RESUMEN

La presente investigación tiene como propósito describir el cumplimiento de las obligaciones tributarias del impuesto al valor agregado en la empresa Servi Petrol, C.A., la metodología fue de tipo descriptiva, con un diseño documental, transeccional. La población objeto del estudio fueron los documentos contentivos de la información sobre los deberes formales y materiales de la empresa. Para la recolección de los datos se utilizó la técnica de la observación documental. El análisis de los datos, se realizó mediante el análisis de contenido. Los resultados reflejaron que la empresa mantiene un mediano cumplimiento de las obligaciones tributarias del IVA. Como conclusión se afirma que la empresa no cumple en forma correcta con sus obligaciones tributarias, razón por la cual está expuesta a sanciones tipificadas en el Código Orgánico Tributario (2008), en sus artículos 101, 102, 103 y 104.

Palabras clave: Tributos; obligaciones; derechos formales, materiales
The purpose of this research is to describe the fulfillment of the tax obligations of the value added tax in the company Servi Petrol, C.A., the methodology was descriptive, with a documentary, transectional design. The target population of the study were the documents containing the information on the formal and material duties of the company. For data collection, the technique of documentary observation was used. The data analysis was carried out through content analysis. The results reflected that the company maintains a medium compliance with VAT tax obligations. As a conclusion, it is affirmed that the company does not comply correctly with its tax obligations, which is why it is exposed with sanctions typified in the Organic Tax Code (2008), in its articles 101, 102, 103 and 104.

Key words: Tributes; obligations; formal rights, materials

\section{RESUMO}

O objetivo desta pesquisa é descrever o cumprimento das obrigações tributárias do imposto sobre o valor agregado na empresa Servi Petrol, CA, a metodologia foi descritiva, com desenho documental e transversal. A população-alvo do estudo foram os documentos contendo as informações sobre as atribuições formais e materiais da empresa. Para a coleta de dados, foi utilizada a técnica de observação documental. A análise dos dados foi realizada por meio da análise de conteúdo. Os resultados refletem que a empresa mantém um cumprimento moderado das obrigações fiscais do IVA. Em conclusão, afirma-se que a empresa não cumpre corretamente as suas obrigações fiscais, razão pela qual está exposta às sanções tipificadas no Código Tributário Orgânico (2008), nos seus artigos 101, 102, 103 e 104.

Palavras-chave: Tributos; obrigações; direitos formais, materiais 


\section{INTRODUCCIÓN}

$\mathrm{E}$ I Impuesto al Valor Agregado (IVA), después de la primera guerra mundial aparece en la legislación de muchos países y se fue generalizando. En términos generales el IVA es un impuesto nacional a los consumos que tiene que ser abonado por las personas en cada una de las etapas del proceso económico, en proporción al valor agregado del producto, así como sobre la realización de determinadas obras y locaciones, y la prestación de servicios.

En ese orden de ideas, la ley del Impuesto al Valor Agregado en Venezuela, en su artículo 1 señala que el IVA es un tributo correspondiente tanto a bienes muebles, como a la prestación de servicios y la importación de bienes, aplicable en todo el territorio nacional, que deberán pagar las personas naturales o jurídicas, las comunidades, las sociedades irregulares o de hecho, los consorcios y demás entes jurídicos y económicos, públicos o privados, que en su condición de importadores de bienes habituales o no, de fabricantes, productores, ensambladores, comerciantes y prestadores de servicios independientes, realizan las actividades definidas por la ley como hecho imponible.

De lo acotado, se entiende que la declaración del IVA, es una obligación competente a toda empresa, que debe ser realizada mensualmente y cuyo incumplimiento representa, no solo el desacato de la ley, sino también una falta grave que tarde o temprano traerá repercusiones financieras tanto para el negocio como para el estado venezolano, ya que es a través del cobro de los impuestos que se logra recabar gran parte del ingreso que posteriormente servirá de sustento a la mayoría de las funciones de carácter público, tales como la educación, la salud, la seguridad, entre otras.

Hoy en día constituye una importante fuente de generación de ingresos para el financiamiento público a nivel mundial. Por tal motivo, todo país requiere contar con un sistema tributario que le permita, no solo recaudar fondos con el propósito de financiar el gasto público en general, sino también llevar adelante los llamados gastos sociales y de capital y, sobre todo, redistribuir la parte de la renta nacional que es el ingreso fiscal, a fin de generar múltiples beneficios a la población.

En razón de lo antes mencionado, el sistema tributario de cada país crea una serie de impuestos a través de los cuales busca recaudar cantidades de dinero suficientes para soportar parte del gasto público. En este sentido, define las clases de mayor o menor ingresos y sectores sociales (trabajadores, comerciantes, importadores, industriales, otros), así como las diversas obligaciones tributarias que deben cumplir.

En el caso particular del sistema tributario venezolano, González (2015), señala que el mismo representa la herramienta idónea con que cuenta el Estado para el logro de los objetivos trazados en su política fiscal, la cual ha evolucionado y madurado gradualmente para lograr la integración entre las características de los tributos que la conforman con las particularidades y necesidades económicas del país.

Cabe destacar, que las disposiciones legales que regulan el sistema tributario venezolano, han sido modificadas y reformadas en la medida que las condiciones económicas lo han 
ameritado. Por consiguiente, hoy en día el cumplimiento de las obligaciones tributarias es considerado elemento importante de la economía del país, puesto que el mismo permite cubrir los gastos públicos o partidas que realiza el gobierno a través de inversiones públicas.

En tal sentido, se ha creado el impuesto sobre la renta, el impuesto a las bebidas alcohólicas, al tabaco, a las importaciones, a las transacciones financieras, y el impuesto al valor agregado, entre otros, los cuales tienen como finalidad generar mayores ingresos a la nación mediante el pago obligatorio de porcentajes específicos de dinero, por parte de las diversas clases y sectores sociales.

Respecto al Impuesto al Valor Agregado (IVA), el mismo es definido por Cedeño y Díaz (2004), como un impuesto indirecto que se aplica sobre el consumo y que resulta financiado por el consumidor final; este es percibido por el vendedor en el momento de toda transacción comercial (transferencia de bienes o servicios). Su alícuota, varía de acuerdo con las necesidades de cada país.

Cabe destacar, que el IVA fue implantado en Venezuela en el año de 1993, mediante ley publicada en la Gaceta Oficial n 35304 del 24/09/93 y entro en vigencia el 1 de octubre del mismo año, aplicándose la alícuota impositiva general de diez por ciento (10\%) a todas las operaciones, y en el caso de exportaciones cero por ciento (0\%). Posteriormente, se incluyó la alícuota adicional del quince por ciento (15\%) a las operaciones que tuvieran por objeto ciertos bienes y servicios suntuarios; esta alícuota adicional se aplicó desde el $1^{\circ}$ de enero de 1994, según reforma de la ley.

El 1 de agosto de 1994, el IVA pasa a ser Impuesto al consumo suntuario y a las ventas al mayor, manteniendo la misma alícuota impositiva general a todas las operaciones. Esta ley sufrió una modificación, en septiembre del mismo año, sin variar la alícuota del impuesto. A partir del 1 de enero de 1995, con la entrada en vigencia de la ley de presupuesto de ese año, la alícuota del ICSVM correspondió a doce y medio por ciento $(12,5 \%)$ hasta el 1 de agosto de 1996, fecha en que entra en vigencia la modificación del impuesto en donde se aumenta a diez y seis y medio por ciento $(16,5 \%)$.

En el año 1999, vuelve nuevamente a ser IVA, según publicación en la Gaceta Oficial N 5363 Extraordinario, de fecha 12 de julio de 1999, vigente a partir del 1 de junio del mismo año, estableciendo la aplicación de una alícuota general del quince y medio por ciento $(15,5 \%)$, salvo en los casos de importaciones, venta de bienes y prestación de servicios en el Puerto Libre del Estado Nueva Esparta que correspondía al ocho por ciento (8\%), y la alícuota del cero por ciento (0\%) para las exportaciones.

Según Rivas (2002), el IVA se ha mantenido desde entonces, pero ha sido objeto de diversas reformas, iniciadas desde el año 2000, con la única variación de la alícuota impositiva, la cual, desde el 1 de abril de 2009 hasta la actualidad, se ubica en 12\%.

Cabe destacar, que la determinación del IVA se lleva a cabo a través de la administración tributaria, que tiene las facultades de recaudar los tributos, intereses, sanciones y otros accesorios además de ejecutar procedimientos de verificación, fiscalización y determinación para que así todos estos ingresos recaudados sean pasados al Estado y éste cumpla su función de satisfacer las necesidades del colectivo. Por otro lado, el sector de pequeña y 
medianas empresas en el país, constituye una amplia y sólida base tributaria para el tesoro nacional por su gran diversidad de actividad económica que a través de ellas se desarrolla.

Sin embargo, a pesar de las disposiciones y acciones legales, normativas y promocionales que el Servicio Nacional Integrado de Administración Aduanera y Tributaria (Seniat) ha implementado, y siendo que ciertamente las metas de recaudación han sido cumplidas a nivel nacional, persisten aún situaciones que demuestran el incumplimiento de manera integral de los contribuyentes ya sean formales, ordinarios o especiales; quienes en ocasiones evaden el pago de este impuesto por causa del desconocimiento, la mala interpretación y la irresponsabilidad.

En el caso particular de la empresa Servi Petrol, C.A., la cual se califica como contribuyente ordinario, por cuanto es prestadora habitual de servicios de naturaleza jurídica y como parte de su giro, objeto u ocupación, realiza actividades, u operaciones, que constituyen hechos imponibles, se ha detectado a través de la revisión de datos contables diversas irregularidades asociadas con la elaboración de los libros de compras y ventas, así como en los registros de ingresos y egresos, las cuales se presume que incidieron en las correspondientes declaraciones del IVA, constituyéndose en hechos irregulares.

Lo antes expuesto induce a afirmar que esta empresa desconoce con precisión la forma en que da cumplimiento a los deberes tributarios del IVA. De continuar esta situación se arriesga a ser sancionada por el órgano rector del impuesto (Seniat), lo cual incluye sanciones económicas hasta su cierre definitivo.

Ante lo cual se hace necesario que en la empresa Servi Petrol, C.A. se describan los procesos relacionados con tales deberes, a los fines de identificar y caracterizar los obstáculos y debilidades que ellos han implicado para la organización, para asegurar el cabal cumplimiento del ordenamiento jurídico establecido e impedir la aplicación de sanciones por incumplimiento de normas tributarias.

\section{Marco teórico}

Luqui (como se citó en Martínez 2009), define la obligación tributaria como aquella obligación que une al ciudadano-contribuyente con el Estado, mediante ese vínculo que lo constriñe al cumplimiento de una prestación de dar una suma de dinero (sujeto pasivo de la obligación tributaria). La causa de esa unión y correlativo constreñimiento, es que dicho constreñimiento, es que dicho ciudadano-contribuyente goza y se ve favorecido por las seguridades y ventajas que el Estado les presta a su trabajo, riqueza y libertad, por medio de las funciones públicas (defensa, seguridad, justicia) y de los servicios públicos generales (sanidad, higiene, educación, entre otros)

De esta manera, se reconoce la obligación tributaria como el vínculo que se establece por ley entre el estado y el deudor tributario reconocido como personas naturales o jurídicas y que genera una serie de deberes y derechos regidos por la normativa legal.

La Obligación Tributaria incluye los siguientes aspectos: 


\section{Base Imponible}

Es la medición del tributo, en el caso del IVA deben ejecutarse las tareas liquidatarias que la ley establezca, partiendo del precio gravable de cada uno de los hechos imponibles. El Glosario de Tributos Internos del Seniat (s/f) la define la base imponible como:

Magnitud susceptible de una expresión cuantitativa, definida por la ley que mide alguna dimensión económica del hecho imponible y que debe aplicarse a cada caso concreto a los efectos de la liquidación del impuesto. Valor numérico sobre el cual se aplica la alícuota del impuesto. Cantidad neta en relación con la cual se aplican las tasas del impuesto. (p. 5)

La ley del IVA establece el procedimiento a seguir para proceder a calcular la base imponible en cada una de los casos presentes (venta de bienes muebles, ventas de alcoholes, licores y demás especies alcohólicas o de cigarrillos y demás manufacturas del tabaco, importación de bienes, prestación de servicios nacionales o provenientes del exterior).

\section{Adiciones a la base imponible}

El artículo 23 contempla que, para determinar la base imponible correspondiente a cada período de imposición, deben computarse todos los conceptos que se carguen o cobren en adición al precio convenido para la operación gravada, cualesquiera que ellos sean.

- Deducciones a la base imponible. La ley del IVA, en su artículo 24, establece que se deben deducir de la base imponible las rebajas de precios, bonificaciones y descuentos normales del comercio, otorgados a los compradores o receptores de servicios en relación con hechos determinados, tales como el pago anticipado, el monto o el volumen de las operaciones.

- Las alícuotas impositivas. El término alícuota es la "cantidad fija, porcentaje o escala de cantidades que sirven como base para la aplicación de un gravamen. Cuota parte proporcional de un monto global que determina el impuesto a pagar" (Glosario de tributos internos del Seniat, s/f, p. 4). En el caso del IVA, la alícuota impositiva general aplicable a la base imponible será fijada en la ley de Presupuesto Anual y está comprendida entre un límite mínimo de ocho por ciento (8\%) y un máximo de dieciséis por ciento (16\%).

- Cuota tributaria. La cuota tributaria es el resultado de aplicar el porcentaje a la base imponible, tal como lo establece el artículo 28 de la ley del IVA

- Período de imposición. El período de imposición en el IVA es de un (1) mes calendario, en razón de que cada año civil está compuesto por doce (12) períodos, es decir, que se debe calcular y pagar el impuesto doce (12) veces, tal como lo refiere el artículo 32 de la ley del IVA.

- Determinación de débitos y créditos fiscales. A través del mecanismo de determinación de débitos y créditos se obtiene el IVA que le corresponde pagar al contribuyente. Donde el débito fiscal está representado por el impuesto que el contribuyente ordinario ha 
recibido con ocasión de las ventas y servicios prestados, representando la obligación que adquiere el contribuyente con la Administración Tributaria cada vez que realiza una venta o presta un servicio que este gravado con este impuesto. En tanto que, el crédito fiscal, está representado por el impuesto que ha cancelado el contribuyente por los bienes y servicios gravados que ha recibido de sus proveedores.

- Regímenes de recuperación de créditos fiscales. Uno de los beneficios fiscales que se encuentran consagrados en la ley del IVA es la recuperación de créditos fiscales por los exportadores, es decir, que los contribuyentes ordinarios que realicen exportaciones de bienes o servicios de producción nacional, tienen derecho a recuperar los créditos fiscales soportados por la adquisición y recepción de bienes con ocasión de su actividad de exportación.

\section{Deberes Formales}

Los deberes formales son las obligaciones que deben cumplir los sujetos pasivos. De conformidad con el Glosario de Tributos Internos del Seniat (s/f, p. 9) estos deberes se definen como obligaciones impuestas por el Código Orgánico Tributario (2008), o por otras normas tributarias a los contribuyentes, responsables o determinados terceros". En el caso del IVA, objeto de análisis de esta investigación, los deberes formales, según la ley del IVA, están constituidos por: la inscripción en los registros correspondientes, la declaración, la emisión de documentos y la elaboración de los libros o registros contables, cada uno de los cuales se define a continuación:

- Inscripción en los registros correspondientes. Los contribuyentes y responsables del impuesto deben inscribirse en el Registro de Información Fiscal (RIF) ante la Gerencia Regional de Tributos Internos con jurisdicción en su domicilio fiscal. En aquellos casos en donde el contribuyente incumpla con la formalidad de la inscripción, la Administración Tributaria procederá de oficio, imponiéndole la sanción pertinente. Los contribuyentes que califiquen como ordinarios no podrán desincorporarse, a menos que cesen en el ejercicio de sus actividades o pasen a realizar exclusivamente actividades no sujetas, exentas o exoneradas, sin perjuicio del registro existente para los contribuyentes formales del impuesto.

- Declaración. Los sujetos pasivos, bien sea en calidad de contribuyentes, responsables y terceros, están obligados a declarar y pagar el impuesto que corresponda, en este caso, el IVA, en el lugar, fecha y forma que señale el Reglamento (artículo 47 ley del IVA). En este artículo también se hace mención a las normas complementarias para presentar las declaraciones por parte de los sujetos pasivos, y en especial la obligación de los adquirentes de bienes o receptores de servicios, así como de entes del sector público, de exigir al sujeto pasivo las declaraciones de periodos anteriores para tramitar el pago correspondiente. En cuanto al caso de las importaciones, las mismas están establecidas en el artículo 48 de la ley in comento. 
- Emisión de Documentos. Algunos autores hacen mención a que el IVA es un impuesto eminentemente documental, se dice esto debido a que las facturas y documentos equivalentes amparan el cobro del impuesto. Las facturas constituyen un dispositivo o mecanismo de control fiscal, mediante el cual se puede realizar el cruce de información entre los diferentes sujetos pasivos de este impuesto y las mismas se deben emitir cumpliendo las disposiciones contenidas en la Gaceta Oficial 39795 del 8 Noviembre 2011. La ley también establece que los contribuyentes tienen la obligación de registrar contablemente todas sus operaciones y llevar los registros y archivos adicionales que sean necesarios.

La Administración Tributaria podrá sustituir la utilización de las facturas en los términos previstos en esta ley, por el uso de sistemas, máquinas o equipos que garanticen la inviolabilidad de los registros fiscales, así como establecer las características, requisitos y especificaciones que los mismos deberán cumplir.

La factura o documento de que se trate deberá cumplir con una serie de requisitos, cuyo incumplimiento de cualquiera de ellos ocasiona que el impuesto incluido en el documento no genere crédito fiscal.

\section{Libros o registros contables}

La ley es específica en especial, al establecer que los contribuyentes deberán registrar contablemente todas sus operaciones, incluyendo las que no fueren gravables con el IVA, así como las nuevas facturas o documentos equivalentes y las notas de crédito y débito que emitan o reciban, en los casos de nuevas facturas por devoluciones en ventas.

Asimismo, los contribuyentes deberán llevar los libros, registros y archivos adicionales que sean necesarios para el cumplimiento de las disposiciones establecidas en la ley del IVA y su Reglamento. En este sentido, se debe llevar un libro de compras y otro de ventas, además de los libros exigidos por el Código de Comercio (en caso de comerciantes), en los que se reflejen de forma cronológica todas y cada una de las operaciones que se realicen, incluyendo las que no fueren gravables con el impuesto, así como las nuevas facturas o documentos equivalentes y las notas de débito o crédito que emitan o reciban.

Estos instrumentos se realizan y se llenan en base a las disposiciones establecidas en el Reglamento de la ley del IVA, en sus artículos del 70 al 77, y se deben mantener permanentemente en el establecimiento del contribuyente.

\section{Deberes materiales}

Los deberes materiales se pueden definir como las obligaciones impuestas por el Código Orgánico Tributario (2008), o por otras normas tributarias a los contribuyentes, responsables o determinados terceros, relativos al pago del tributo. Todas las obligaciones tributarias se fundamentan en la máxima constitucional conforme a la cual toda persona tiene el deber de coadyuvar a los gastos públicos mediante el pago de impuestos, tasas y contribuciones que establezca la ley. 
Los deberes tributarios materiales están relacionados con el pago de los tributos, y tiene su origen en la obligación que conforma la obligación jurídica tributaria, una vez acaecido el hecho generador. En efecto, los contribuyentes, una vez ocurrido el hecho imponible cuya realización origina el nacimiento de la obligación tributaria deben determinar la cuantía del tributo, es decir, el monto.

Los deberes tributarios materiales están relacionados con el pago de los tributos; tienen que ver con dinero. Se encuentran tipificados en el Código Orgánica Tributario (COT), en el artículo 109. Para realizar el pago, como medio de extinción de la obligación tributaria, deben estar definidas tres premisas dispuestas en el Código Orgánico Tributario (2008), las cuales son:

\section{Deber de pago}

El deber de pago implica determinar la cuantía del tributo y realizar el pago correspondiente. Las personas naturales, las personas jurídicas y las entidades sin personalidad jurídica, deberán presentar electrónicamente sus declaraciones del impuesto al valor agregado. La declaración se debe efectuar en la planilla de IVA identificado como Forma 30 a través de la página del Portal del Seniat y presentarse dentro de los quince (15) días continuos siguientes al período de imposición o mes calendario en el que se realizó la venta o prestación de servicios.

Efectuada la declaración, en los casos en que la misma arroje impuesto a pagar, el contribuyente podrá optar entre efectuarlo electrónicamente o imprimir la planilla de pago generada por el sistema, (las cuales deben ser 5) ante las oficinas receptoras de fondos nacionales, a saber, las entidades bancarias autorizadas.

La declaración del IVA debe presentarse aun cuando en ciertos períodos de imposición no haya lugar a pago de impuesto, ya sea porque no se ha generado debito fiscal, el crédito fiscal es mayor que el débito fiscal, o el contribuyente no ha realizado operaciones gravadas en uno o más períodos tributarios, salvo que haya cesado sus actividades y lo haya comunicado a la Administración Tributaria.

Cuando los sujetos pasivos no hubieren declarado y pagado el impuesto establecido en esta ley, o en cualquier otro supuesto establecido en el Código Orgánico Tributario (2008), la Administración Tributaria podrá proceder a la determinación de oficio.

\section{Oportunidad del pago}

Debe efectuarse en la fecha y lugar que al respecto imponga la normativa tributaria. Los contribuyentes y, en su caso, los responsables según la ley, están obligados a declarar y pagar el impuesto correspondiente en el lugar, la fecha y la forma que establezca el Reglamento.

Deberán presentar declaración jurada por las operaciones gravadas y exentas, realizadas en cada período mensual de imposición. En dicha declaración dejarán constancia de la suma de los débitos fiscales que consten en las facturas emitidas en el período de imposición, así como de las sumas de los impuestos soportados y que le han sido trasladados como créditos fiscales en las facturas recibidas en el mismo período; las notas de débito 
y crédito correspondientes; el impuesto retenido o percibido en el período de imposición como responsable a título de agente de retención o de percepción o en otra calidad de responsable del impuesto.

\section{Exactitud en el monto pagado}

El contribuyente se encuentra obligado a pagar el tributo en su exacta cuantía. Así mismo, deberán declarar si existieren excedentes de crédito fiscal del período de imposición anterior, y determinar el impuesto por pagar o, si correspondiere, indicar en la misma el excedente del crédito fiscal resultante. (Artículo 59 Reglamento ley del IVA).

\section{El Impuesto al Valor Agregado (IVA)}

El IVA, según Moya (2006), se define como "un tributo que grava la enajenación de bienes muebles, la prestación de servicios y la importación de bienes, aplicable en todo el territorio nacional, el cual deben pagar las personas naturales o jurídicas, las comunidades, las sociedades irregulares 0 , de hecho, los consorcios y demás entes jurídicos y económicos, públicos o privados, que realizan las actividades definidas por la ley como hechos imponibles. La ley del Impuesto al Valor Agregado en su artículo $1^{\circ}$ señala lo siguiente:

Es un tributo que grava la enajenación de bienes muebles, la prestación de servicios y la importación de bienes, aplicable en todo el territorio nacional, que deberán pagar las personas naturales o jurídicas, las comunidades, las sociedades irregulares o de hecho, los consorcios y demás entes jurídicos y económicos, públicos o privados, que en su condición de importadores de bienes habituales o no, de fabricantes, productores, ensambladores, comerciantes y prestadores de servicios independientes, realizan las actividades definidas por la ley como hecho imponibles en esta ley. $(\mathrm{s} / \mathrm{n})$.

En este sentido, Villegas (2002), sostiene que el IVA es una derivación de los impuestos a las ventas; tributos estos que económicamente inciden sobre los consumos, bajo la denominación genérica de impuestos al consumo se comprende aquellos que gravan en definitiva y como su nombre lo indica, al consumidor de un determinado bien.

Se puede definir, entonces al IVA, como un tributo que grava el valor añadido de todas las transacciones u operaciones económicas, en cada una de sus etapas de la cadena de circulación de los bienes hasta llegar al consumidor final o consumidor pasivo, a excepción de aquellas operaciones consideradas por disposición de la ley del Impuesto al Valor Agregado como exentas del pago de dicho tributo. También se puede definir como el impuesto a las actividades de comercialización o de compra y venta de los bienes y servicios en todas sus etapas hasta llegar al consumidor final. 


\section{MÉTODO}

$\mathrm{E}$ estudio se consideró descriptivo, con un diseño documental. Con respecto a la perspectiva temporal el diseño se consideró transeccional contemporáneo. Las unidades de estudio estuvieron representadas por los documentos, específicamente los libros de contabilidad, los libros de compras y ventas, las declaraciones de IVA, las facturas de compras, las facturas de ventas.

La técnica utilizada fue el análisis documental con un instrumento matriz de análisis. Una vez registrada la información de interés, se empleó la técnica de análisis de contenido, la cual permitió interpretar los datos relacionados con los diversos indicadores definidos.

Finalmente, para el análisis de los datos, se utilizó la técnica de análisis de contenido. Mediante una lectura general de la información se inició la búsqueda y observación de los hechos presentes en los materiales escritos consultados de interés para esta investigación.

\section{RESULTADOS}

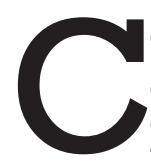

on relación a identificar los deberes formales con respecto al cumplimiento de las obligaciones tributarias del IVA, a las que está sujeta la empresa Servi Petrol, C.A. los resultados indican con respecto a la inscripción en el registro se observó un parcial cumplimiento del deber formal.

Con relación al deber formal de presentar las declaraciones (planillas de IVA) mediante la evaluación realizada se constató que la empresa cumple con la presentación y pago del impuesto; lo que se sustentó en la revisión realizada de las planillas electrónicas forma $\mathrm{n}^{\circ} 30$, donde se determinó mediante fechas de pago, que las presentaciones de dichas declaraciones se encuentran dentro de los plazos establecidos a los que se refiere el artículo 47 de la ley del impuesto al valor agregado.

De igual manera, en lo que respecta al deber formal sobre emisión de documentos (facturas), se observó que la empresa cumple su obligación y emite las facturas por concepto de los servicios prestados a sus clientes; cumpliendo así con el deber formal tipificado en la providencia administrativa $n^{\circ} 0257$ emitida por el Servicio Nacional Integrado de Administración Aduanera y Tributaria (Seniat).

En cuanto al deber formal relativo a los libros contables se pudo constatar que la empresa dentro de sus libros y registros que presentan ante el Seniat se encuentran: el libro diario, el mayor, el de inventarios, libro auxiliar de ventas y libro auxiliar de compras. Por otra parte, se comprobó a través de los datos suministrados por la empresa, que el libro auxiliar de ventas no cumple con las formalidades legales establecidas en la ley, por cuanto no lleva un orden cronológico, orden consecutivo del número de factura y control, con referencia al contenido de los datos generales del adquiriente del servicio; se observó que en el caso de las personas jurídicas algunos de los registros de razón social estaban incompletos, así como también se determinaron errores en las bases y cálculos del impuesto. 
En base a la revisión y análisis del libro auxiliar de compras se pudo comprobar que el mismo no es llevado de forma ordenada, ni cronológica en cuanto a la fecha de las facturas, los registros de la razón social de sus proveedores, tanto de personas naturales como de personas jurídicas, están incorrectos en cuanto a los datos presentados; asimismo, fueron tomado en cuantas facturas de compras que no pertenecían a la empresa y fueron declaradas en las planillas de IVA forma 30.

Además, se determinó que se presentaron errores y omisiones en los libros de compras y ventas, lo cual indica un incumplimiento de acuerdo al Código Orgánico Tributario (2008), que establece las respectivas sanciones en sus artículos:

Artículos 101. Constituyen ilícitos formales relacionados con la obligación de emitir y exigir comprobantes: 1) no emitir facturas u otros documentos obligatorios; 2) no entregar las facturas y otros documentos cuya entrega sea obligatoria; 3) emitir facturas u otros documentos obligatorios con prescindencia total o parcial de los requisitos y características exigidos por las normas tributarias; 4) Emitir facturas u otros documentos obligatorios a través de máquinas fiscales, sistemas de facturación electrónica u otros medios tecnológicos, que no reúnan los requisitos exigidos por las normas tributarias; 5) no exigir a los vendedores o prestadores de servicios las facturas, recibos o comprobantes de las operaciones realizadas, cuando exista la obligación de emitirlos; 6) emitir o aceptar documentos o facturas cuyo monto no coincida con el correspondiente a la operación real.

Artículo 102. Constituyen ilícitos formales relacionados con la obligación de llevar libros y registros especiales y contables: 1) no llevar los libros y registros contables y especiales exigidos por las normas respectivas; 2) llevar los libros y registros contables y especiales $\sin$ cumplir con las formalidades y condiciones establecidas por las normas correspondientes, o llevarlos con atraso superior a un (1) mes.

En cuanto a la base imponible se determinó que presentaba errores. Ahora bien, según el Seniat (s/f) la base imponible se define como el elemento cuantitativo sobre el cual se aplica la alícuota tributaria para determinar el impuesto, en consecuencia, quedó comprobado que los cálculos de los impuestos causados no se correspondían con las bases imponibles declaradas y lo cual puso en evidencia el incumplimiento en cuanto a los errores presentes en cálculos, lo que, según el Código Orgánico Tributario (2008), en su artículo 102 numerales 5 y 7 , se acarrean sanciones cuando se lleven los libros y registros contables y especiales sin cumplir con las formalidades y condiciones establecidas por las normas correspondientes, así como al llevarlos con atraso superior a un (1) mes.

En cuanto al libro de ventas, el mismo fue presentado de forma correcta, al comprobarse que la alícuota impositiva aplicada fue la misma alícuota gravada vigente. En cuanto al libro de compras, se pudo visualizar que la empresa registraba siempre las operaciones gravadas sin tomar en cuenta las compras exentas en las operaciones día por día.

Es decir, que la empresa aplica la alícuota impositiva a las compras exentas de impuesto y las declara en sus correspondientes periodos, lo cual indica que nunca registran las compras como lo establece el artículo 56 de la Ley del IVA y su Reglamento, debido a que no se separan las compras exentas de las gravadas. Lo cual constituye un ilícito tributario 
formal relacionado con la obligación de llevar los libros y registros contables especiales, sin cumplir con las formalidades y condiciones establecidas por las normas correspondientes según lo establece el artículo 102 del Código Orgánico Tributario (2008).

Con respecto a la cuota tributaria, con base al análisis realizado se observó que no son reales ni confiables, debido a que se presentaron incumplimiento en la base imponible y las alícuotas impositivas, lo que arroja un ilícito formal relacionado a la obligación de llevar los libros y registros contables especiales, sin cumplir con las formalidades y condiciones establecidas por las normas correspondientes según lo establece el artículo 102 del Código Orgánico Tributario (2008).

En cuanto a los periodos de imposición, según verificación de las planillas forma 30, todas cumplen con el periodo de imposición en las fechas establecidas por la legislación venezolana para la declaración del IVA como contribuyente ordinario del IVA, la cual establece que debe presentarse dentro de los quince (15) días continuos siguientes al período de imposición o mes calendario en el que se realizó la venta o prestación de servicios.

Con relación a la determinación de los débitos y créditos fiscales, en cuanto a los débitos fiscales se observaron inconsistencias, pues al comparar el físico de las facturas de ventas con las declaraciones no se correspondían; así como también se observó facturas de ventas que fueron anuladas sin presentar las originales $y$, posteriormente, algunas fueron declaradas como servicios cobrados.

En lo que respecta a los créditos fiscales, se tomaron créditos fiscales que no cumplían con las normas de emisión de facturas establecidas en la providencia administrativa 0257 por parte del Seniat. Lo que indica un nivel alto de incumplimiento en cuanto a la determinación de los débitos y créditos fiscales en las declaraciones presentadas al Seniat. Además, esta situación se considera un ilícito tributario en cuanto al deber formal, al llevar los libros y registros contables especiales sin cumplir con las formalidades y condiciones establecidas por las normas correspondientes (Código Orgánico Tributario, 2008, Artículo 102).

Por último, se presentó el régimen de recuperación de créditos fiscales que no aplica en la empresa objeto de la investigación.

En consecuencia, de acuerdo con los aspectos anteriormente analizados se observó que la empresa Servi Petrol, C.A presenta un cumplimiento favorable de las obligaciones tributarias de los deberes formales, según lo establecidos en la ley de Impuesto al Valor Agregado, sin embargo es importante resaltar que la empresa debe revisar lo referido al cumplimiento de los libros contables (libros de compras y libros de ventas) para dar fiel cumplimiento a lo establecido en la ley del IVA y el reglamento de la ley del IVA y de esta manera evitar las sanciones contempladas en el artículo 102 del Código Orgánico Tributario (2008).

Con relación a los deberes materiales con respecto al cumplimiento de las obligaciones tributarias del IVA, a las que está sujeta la empresa Servi Petrol, C.A., los resultados, indicaron que los deberes materiales como lo son, el deber del pago y la oportunidad de pago presentaron un cumplimiento favorable. 
Caso contrario, se pudo notar con relación al deber material de la exactitud del pago, ya que los resultados no fueron confiables, puesto que aun cuando se pagaba con puntualidad se evidenció un incumplimiento, ya que, se observaron errores de inexactitud en los cálculos en cuanto a los deberes formales, tales como la base imponible, los débitos y créditos fiscales y la alícuota impositiva, que están relacionados directamente deber material mencionado.

Es importante resaltar en este aspecto que a pesar de que existe un cabal cumplimiento según lo expuesto en el Código Orgánico Tributario, la inexactitud de los cálculos genera un monto de pago incorrecto, lo cual a la larga puede perjudicar el correcto y legal cumplimiento de las obligaciones tributarias.

Con relación a determinar el nivel de cumplimiento de las obligaciones tributarias del IVA en la citada empresa, se consideró que la obligación tributaria es el vínculo que relaciona al Estado con los contribuyentes, haciéndolos responsables con la satisfacción de las necesidades colectivas a través del pago del impuesto. Sin embargo, esta obligación no se limita solo al pago, los contribuyentes deben cumplir una serie de requisitos establecidos en los deberes formales y materiales del Impuesto al Valor Agregado.

Así, para la primera dimensión de estudio referida al cumplimiento de las obligaciones tributarias en relación al IVA que posee la empresa Servi Petrol, C.A se pudo comprobar que hasta ahora siempre han cumplido con lo que establece la ley del IVA en cuanto a la inscripción en el registro, la emisión de documentos, facturas, declaración en los periodos de imposición correspondientes.

Con referencia a los indicadores relacionados con los deberes formales de los libros contables (libro de compras y libros de ventas), la base imponible, las alícuotas impositivas, se pudo observar que la empresa no cumple en forma correcta con sus obligaciones tributarias razón por la cual están expuestos a sanciones tipificadas en el Código Orgánico Tributario (2008), en sus artículos 101, 102, 103 y 104.

Finalmente, en lo que respecta a los deberes materiales referidos al indicador deber del pago y oportunidad del pago se determinó un efectivo cumplimiento de las obligaciones tributarias. Por otra parte, el indicador exactitud del pago se evidencio un incumplimiento parcial ya que este indicador se ve directamente afectado por los errores y omisiones de los deberes formales objetos de sanciones.

\section{CONCLUSIONES}

$\mathrm{E}$ n atención a las amplias facultades en materia tributaria, la investigación tuvo como propósito fundamental describir el nivel de cumplimiento de las obligaciones tributarias del IVA en la Empresa Servi Petrol, C.A; se aplicó como herramienta útil la revisión documental en el área tributaria, es por ello que después de lo antes expuesto se pudo llegar a las siguientes conclusiones:

En tal sentido con respecto a los deberes formales es posible establecer que la empresa Servi Petrol, C.A cumple medianamente los deberes formales. Se evidenció que, si bien es consecuente con la mayoría de los requisitos exigidos por la ley del IVA, aun presenta 
algunas dificultades en el cumplimiento de los mismos en cuantos a los deberes formales de la base imponible, el libro contable de compras, alícuota impositiva y determinación de débitos y créditos.

Con relación a los deberes materiales se determinó que la empresa Servi Petrol, C.A cumple medianamente sus obligaciones materiales que le corresponden en cuanto al impuesto al valor agregado, acotando que presentan dificultad en cuanto a la exactitud del pago vinculado a los indicadores de la base imponible, determinación de créditos y débitos y alícuotas impositivas.

De manera general se concluye que a pesar que la empresa cumple parcialmente y medianamente con los deberes formales y materiales, esto no resulta suficiente, es necesario y obligatorio cumplir todas y cada una de las obligaciones que le competen. De este modo se evitan cierres temporales y multas que causen molestias y gastos en los que no se incurriría si se toman las medidas necesarias y pertinentes para cumplir con los deberes establecidos en las normas, leyes, reglamentos y providencias emitidas por el ejecutivo nacional u órgano rector en la materia.

\section{REFERENCIAS}

Cedeño, G y Días V. (2004). El IVA una década de Jurisprudencia en Venezuela (1994-2004). Editorial Torino. Caracas, Venezuela

Código Orgánico Tributario (2008). Gaceta Oficial de la República Bolivariana de Venezuela, 38855 del 22 de enero de 2008. Caracas, Venezuela

González, A. (2015). Cumplimiento de los deberes formales en materia del Impuesto al Valor Agregado (IVA) por los contribuyentes ubicados en la avenida constitución de Santa Rita municipio Francisco Linares Alcántara del estado Aragua. (Tesis). Universidad de Carabobo. Venezuela

Martínez, M. (2009). El hecho imponible, en derecho financiero y tributario, http:// www.iustel.com. Base de datos IUSTEL, Documento RI §911733, (ESP): Portal Derecho, S.A., IUSTEL

Moya, E. (2006). Elementos de finanzas públicas y derecho tributario. Segunda Edición
Reglamento General ley Impuesto al Valor Agregado, publicado el 12 julio 1999, en Gaceta Oficial No.5363 Extraordinaria. Venezuela: Oficina de información y comunicación

Rivas, J. (2002). Los tributos. México: Editorial Limusa

Seniat. Providencia mediante la cual se establece las normas generales de emisión de facturas y otros. Documentos. Gaceta oficial 39795 del 8 noviembre 2011

Seniat (s/f). Glosario de tributos internos. Venezuela: Oficina de información y comunicación

Seniat. Ley de Reforma Parcial del Impuesto al Valor Agregado. Gaceta Oficial $\mathrm{N}^{\circ}$ 37.999 Extraordinaria de fecha 11/08/04. [Página web]. Disponible. www.seniat. gov.ve

Seniat. Ley del Impuesto al Valor Agregado [página web]. Disponible. www.seniat. gov.ve 
Seniat. Providencia Administrativa No. Villegas, H. (2002). Derecho Financiero y SNAT/2002/1.455

Seniat. Providencia Administrativa

No. SNAT/2005/0056 [página web].

Disponible. www.seniat.gov.ve 